\title{
Assessment of Tinea Capitis' Exposure, Knowledge and Preventive Behavior among Residents of Teso South Sub County, Busia County
}

\author{
Ogombo Concilia M, Wanzala Maximilla, Were Tom
}

\begin{abstract}
The study focused on exposure, knowledge and preventions behaviour of Tinea Capitis skin disease among residence of Teso South Sub County of Busia County Kenya. In 2017, Global burden of disease (GBD) placed fungal skin diseases $4^{\text {th }}$ on the top 10 most prevalent diseases worldwide, of which Tinea capitis is one of the fungal skin infections. From Busia County- Kenya, Health Sector Strategic and Investment Plan 2018-2023 report, skin diseases was $3^{\text {rd }}$ leading cause of morbidity in the county with $6.5 \%$; of which Tinea capitis was one of the skin diseases, compelling the study to assess exposure, knowledge and prevention behaviour of residence. A cross sectional descriptive study design was adopted; multi stage sampling techniques was employed. Data was collected using a questionnaire and analyzed using descriptive and inferential statistics. The study revealed that $79 \%$ were exposed to Tinea capitis, 54.6\% had good knowledge on Tinea capitis while 59.6\% presented poor prevention behaviour. There was association of exposure with knowledge on Tinea capitis; and no association of knowledge with prevention behaviour in the community. The exposure percentages were high indicating prevalence of the skin disease. The respondents were knowledgeable on signs and symptoms, and transmission of the disease, but less knowledgeable on the cause and risk factors of Tinea capitis. Poor prevention behaviour was noted and could be attributed to poor economic status as this increased sharing of basic equipment and facilities that exposed them more. Also, lack of higher education in the community presented by almost a quarter of the study respondents who had attained post-secondary education could as well be associated to the poor prevention behaviour.
\end{abstract}

Index Terms-- Exposure, Knowledge, Preventive behaviour, Tinea capitis.

\section{INTRODUCTION}

A Tinea Capitis infection has persisted as a public health problem particularly with overcrowding and sharing of basic grooming equipment, and poor hygiene. The socio economic status of a population contributes to minimizing the spread of the disease or predisposes it to infections. Global Burden of Disease (GBD) estimates noted that 15 categories of skin disease in 187 countries were fungal diseases. Also,

Ogombo Concilia. M, PG Masters Student in Public Health, Department of Public health, Masinde Muliro University of Science and Technology, P.O. Box 190 - 50100, Kakamega, Kenya

Wanzala Maximilla, PhD, Lecturer, Department of Public Health, Masinde Muliro University of Science and Technology, P.O. Box $190-50100$, Kakamega, Kenya

Were Tom, PhD, Lecturer, Department of Medical Laboratory Science, Masinde Muliro University of Science and Technology, P.O. Box 190 50100, Kakamega, Kenya prominence of fungal skin diseases ranked $4^{\text {th }}$ on the top 10 most prevalent diseases worldwide (Hay et al., 2013). Disability Adjusted Life Year (DALY) ranked skin and subcutaneous diseases at $18^{\text {th }}$ globally; and 4th leading cause of nonfatal burden in GBD (Karimkhani et al 2017).

Tinea capitis is a fungal skin infection affecting the scalp. It is mainly caused by Trichophytom tonsurans and Microsporum canis species (Yang et al., 2020); and is endemic in children in many parts of the world, with high prevalence among children in the rural areas (Hay, 2017). In adults, it is more subtle and not well understood since sebum is believed to have protective effects and decreases the risks of infection; and linked to hormonal imbalance in post-menopausal women (Auchus et al., 2016).

Coulibaly et al. (2018), reported that there was a heavy burden of dermaphytosis in Africa, mostly affecting children all over the continent. According to Moto et al. (2015), a study conducted in Kenya, the prevalence rate of dermaphytosis infection is $81.3 \%$. From Busia County Health Sector Strategic and Investment Plan 2018-2023 report, skin diseases was $3^{\text {rd }}$ leading cause of morbidity in the county with $6.5 \%$; of which Tinea capitis was one of the skin diseases. This triggered the study to assess Tinea capitis' exposure, knowledge and preventive behaviour in a rural community in Busia County, with the aim of providing evidences to support the development of a dermatology education programme for the community in order to create awareness through health education and promotion.

\section{MATERIALS AND METHODS}

Study Settings and Population - The study was conducted among the residents ( $\geq 18$ years of age) of Teso South sub-county, Busia County, western Kenya. The sample size was estimated based on Cochran's formula (Cochran, 1963).

Enrolment criteria and Sampling - Multi stage sampling techniques were used to select the different levels of study units. Teso South sub-county was purposively selected based on the high population $(n=165,929)$ (County Government of Busia, Health Sector Strategic and Investment Plan 2018 2023). Convenient sampling technique was used for selecting the Wards in the sub-county according to ease of accessibility and cooperation from the Ward Administrators. All villages in the selected wards were sampled and households in each village were randomly selected. In each household individuals were purposively enrolled into the study with the sample size proportionately distributed among the villages in the selected Wards based on population size. 
Data collection - Data was collected using standardized questionnaires with closed-ended questions; with the assistance of the research assistants, who were trained by the principal researcher in order to familiarize them on the key terms in the questionnaire; and better understand the purpose of the research..

Data Collection Tool and Data analysis -Statistical analysis of data was conducted IBM SPSS Statistics for Windows, Version 25.0. Armonk, NY: IBM Corp. Level of knowledge and preventive behavior on Tinea capitis were assessed using statements based on a 5-point likert scale: +5 (strongly agree) to +1 (strongly disagree) for positive statements, and +5 (strongly disagree) to +1 (strongly agree) for negative statements. 4 statements were used to assess knowledge on the cause of $T$. capitis, 4 on sign and symptoms, 3 on mode of transmission, 6 on risk factors, 7 on knowledge on prevention and 5 on the preventive behaviour. The overall scores for each respondent were summed-up and likert scores $\geq 75^{\text {th }}$ and $<75^{\text {th }}$ percentiles were considered good and poor scores respectively. Age was summarized as median and while knowledge on cause, signs \& symptoms, mode of transmission, prevention, preventive behaviour and the overall knowledge on $T$. capitis were summarized as frequencies and percentages. The Chi-square test was used to determine the distribution of levels of knowledge with exposure to the disease, and levels of knowledge on Tinea capitis with the preventive behaviour in the community. Subsequently all variables with a $P<0.05$ were entered into a multivariate regression model to identify variables most associated with preventive behavior. All tests were two-tailed and $P<0.05$ was considered statistically significant.

Ethical considerations -The study was conducted in accordance with the Helsinki declarations (REFs). Ethical approvals for the study were obtained from Masinde Muliro University of Science and Technology ethical review committee (MMUST/IERC/30/19); permit to conduct the study was obtained from NACOSTI (Ref. No. 946689); and clearance to conduct the study in Teso south sub-county was sort from the Busia County government. Written informed consent was obtained from the authorities in the study area and respondents after explaining the study in a language they understood well. Confidentiality of all information obtained as part of this study was maintained throughout the study.

\section{RESULTS}

\section{Demographic characteristics of the respondents}

The median age of the respondents was 36.0 years, ranging from 18 to 74 years. $50.4 \%(n=201)$ of the study respondents were female; $43.9 \%(\mathrm{n}=175)$ had attained secondary level; $43.1 \%(n=172)$ were self employed; and $43.4 \%(n=173)$ had an average monthly income of less than ksh. 5,000. The demographic data is presented in Table 1.
Table 1: Demographic characteristics of respondents (Residents)

\begin{tabular}{|c|c|c|}
\hline Demographics & Frequency & Percentage \\
\hline Age (Year) & & \\
\hline Median (Range) & \multicolumn{2}{|c|}{$36.0(18.0-74.0)$} \\
\hline \multicolumn{3}{|l|}{ Gender } \\
\hline Female & 201 & 50.4 \\
\hline Male & 198 & 49.6 \\
\hline \multicolumn{3}{|l|}{ Education Level } \\
\hline Post-Secondary & 103 & 25.8 \\
\hline Secondary & 175 & 43.9 \\
\hline Primary & 102 & 25.5 \\
\hline No Formal Education & 19 & 4.8 \\
\hline \multicolumn{3}{|l|}{ Occupation } \\
\hline Employed & 81 & 20.3 \\
\hline Self Employed & 172 & 43.1 \\
\hline Unemployed & 146 & 36.6 \\
\hline \multicolumn{3}{|l|}{$\begin{array}{l}\text { Average Monthly } \\
\text { Income (Ksh) }\end{array}$} \\
\hline Median (Range) & \multicolumn{2}{|c|}{$5,001-10,000(<5000->15$} \\
\hline$<5,000$ & 173 & 43.4 \\
\hline $5,001-10,000$ & 91 & 22.8 \\
\hline $10,001-15,000$ & 77 & 19.3 \\
\hline$>15,001$ & 58 & 14.5 \\
\hline
\end{tabular}

Data are presented as the frequency of respondents (number) and percentages (\%) of respondents unless otherwise indicated.

\section{Respondents" exposure to Tinea capitis}

The results revealed that $79.0 \%$ of the study respondents had been exposed to Tinea capitis.

\section{Respondents knowledge on Tinea capitis}

$11.0 \%$ of the respondents agreed that $T$. capitis was caused by poor personal hygiene while $85.0 \%$ disagreed; $27.5 \%$ agreed that it was caused by poor housing while $46.5 \%$ disagreed; $87.0 \%$ agreed that it was caused by fungal infection while $3.8 \%$ disagreed; and $11.1 \%$ agreed that it was caused by nutritional deficiency while $62.4 \%$ disagreed (Table 2).

$54.9 \%(n=219)$ of the respondents strongly agreed that 'itchy, scaly and bald patches on the head' were signs and symptoms of Tinea capitis; $37.0 \%(\mathrm{n}=148)$ strongly agreed that 'sections of the hair breaking off near the scalp, leaving scaly red areas or bald spots'; $33.3 \%(n=133)$ strongly agreed that 'brittle hair that easily pulls out'; and $22 \%$ ( $=$ 88) strongly agreed that 'painful scalp' were signs and symptoms of $T$. capitis (Table 2).

$85.7 \%$ of the study subjects were of the opinion that direct contact with skin of an infected person would spread Tinea capitis; $66.7 \%$ of the respondents were in support that contact with infected pets/animals would spread the disease; and 


\section{ISSN: 2454-8236, Volume-10, Issue-1, February 2021 Pages 60-65}

$84.7 \%$ supported that the disease could be transmitted through inanimate items to persons.

$86.7 \%$ of the respondents supported that sharing hair brushes and other personal items is a risk; $75.4 \%$ were of the opinion that weakened immune systems is a risk factor; and $77.2 \%$ were in support that age (most commonly toddler and school-age children) is a risk factor to T. capitis (Table 2).

Respondents' knowledge on avoidance of sharing hair brushes and other personal items as a prevention measure was held by a significant percentage of respondents. This was evident from $95.0 \%$ positive response to this respect. Community education (86.9\%) as well as improved nutrition (77.4\%) is believed to prevent the T. capitis. Regular shampooing scored $62.1 \%$; avoiding petting animals that have patches on their skin scored $63.4 \%$; maintenance of regular checkups for all pets scored $70.7 \%$; and reduction in environmental pollution scored $60.7 \%$ (Table 2).

The respondents' knowledge on Tinea capitis was assessed on cause, signs \& symptoms, transmission, risk factors and prevention. Overall respondents' knowledge on Tinea capitis was also assessed; $54.6 \%(n=218)$ of the respondents had good knowledge on $T$. capitis. The results are presented in Table 2 .

The overall respondents' knowledge on Tinea capitis was good, represented by $54.6 \%(n=218)$ of the respondents, although poor knowledge was observed on the cause and the risk factors of the disease. The results are presented in Table 2 .

\section{Respondents' practices towards prevention of Tinea capitis}

$41.6 \%$ of the respondents avoided sharing hair brushes and other personal items very frequently while $34.8 \%$ practice frequently; and $33.8 \%$ very frequently practiced good hygiene while $47.6 \%$ practiced good hygiene frequently. The overall respondents' behaviour towards prevention of Tinea capitis was determined, and it was revealed that $59.6 \%(n=238)$ of the respondents had poor prevention behaviours towards Tinea capitis Table 3 shows the results.

\section{Association of exposure to Tinea capitis with knowledge}

The association of exposure to Tinea capitis and knowledge revealed that; out of the $79.0 \%(n=314)$ of the respondents who were exposed to Tinea capitis, $57.6 \%$ had good knowledge, and out of $54.6 \%(\mathrm{n}=218)$ of the respondents who had good knowledge on Tinea capitis, $83 \%$ were exposed. The results indicated that there was association of exposure to Tinea capitis with respondents' knowledge on the disease since the p-value was 0.02 . The results are presented in Table 4.

\section{Association of knowledge on Tinea capitis with the prevention behaviour}

The association of respondents' knowledge on Tinea capitis with prevention behaviour revealed that; out of $54.6 \%$ ( $\mathrm{n}=$ 218) who had good knowledge on Tinea capitis, $60.6 \%$ had poor behaviour towards prevention of the disease; and out of $59.6 \%(n=238)$ of the respondents who had poor prevention behaviours towards Tinea capitis, $55.5 \%$ had good knowledge on the disease. The study revealed lack of association between knowledge on $T$. capitis with the prevention behaviour given by a p-value of 0.687 . The results are presented in Table 4.

\section{DISCUSSION}

\section{Demographic characteristics of the respondents}

The distribution of respondents by genders was relatively balanced with male participants comprising $49.6 \%$ while female participants comprising of $50.4 \%$ similar to (Aktas and Esin, 2016). The majority (43.9\%) of the respondents had attained secondary school education level; $43.1 \%$ were self-employed, and $43.4 \%$ had an average monthly income of less than Ksh 5,000 similar to (Moto et al., 2015) which reported income of most of the parents $(54.7 \%)$ of the study participants was below Ksh 5,000 and 43.3\% were unemployed.

\section{Exposure to Tinea capitis}

The results revealed that $79.0 \%$ of the study respondents were exposed to Tinea capitis. This was in line with the findings of (Laraqui et al., 2018) which indicated that only $17.4 \%$ of the study participants did not have any skin condition, meaning that majority had skin diseases. The results as well mirrors (Guto et al., 2016) findings which indicated recurrent vaginitis and Tinea capitis account for $82 \%$ of the infections of Kenya's population; and (Hibstu and Kebede, 2017) which reported Tinea capitis accounts for up to $92.5 \%$ of dermatophytoses in children younger than 10 years. Therefore, the high burden of Tinea capitis in Teso Sub-county is a reflection of similar cases in other part of the country.

\section{Respondents' knowledge on Tinea capitis}

The respondents' knowledge on Tinea capitis was good similar to (Mahirah et al., 2015) which reported good knowledge on prevention of scabies among the study participants. However, majority of the respondents presented poor knowledge on the cause and risk factors of Tinea capitis similar to (Laraqui et al., 2018) which reported poor knowledge among $95 \%$ of the study participants. In addition good knowledge was observed on the signs and symptoms, and good knowledge on transmission of $T$. capitis similar to (Bilal et al., 2018) which reported good knowledge on signs and symptoms and mode of transmission of scabies infections among nursing students at Sabia University College;; and good knowledge on prevention of the disease similar to (Mahirah et al., 2015).

\section{Respondents' prevention behaviour towards Tinea capitis} The study recorded poor prevention behaviour towards $T$. capitis contrary to (Mahirah et al., 2017) which reported $60 \%$ moderate practice towards prevention of scabies among the Santri. Moreover, majority of the community members avoided sharing of hair brushes and other personal belongings as a prevention measure towards Tinea capitis similar to (Bilal et al., 2018) which reported $100 \%$ of the nursing students supported that individuals should avoid sharing personal belongings. Similarly, (Adesiji et al., 2019) reported that $57 \%$ of the study participants who shared combs were infected with $\mathrm{T}$. capitis as compared to $11 \%$ who had the infection but did not share combs. A significant percentage of the community practiced personal hygiene to prevent the disease similar to (Alshehri et al., 2018) which reported that $100 \%$ of the medical students supported personal hygiene. The respondents' behaviour on avoiding of animals suggested why the high burden of the disease similar to 
Assessment of Tinea Capitis' Exposure, Knowledge and Preventive Behavior among Residents of Teso South Sub County, Busia County

(Adesiji et al., 2019) which revealed that $66 \%$ of pupils who were playing with animals were infected with $T$. capitis.

Table 2: Knowledge on Tinea capitis

\begin{tabular}{|c|c|c|c|c|c|}
\hline Variable & Strongly agree & Agree & Undecided & Disagree & $\begin{array}{l}\text { Strongly } \\
\text { disagree } \\
\end{array}$ \\
\hline \multicolumn{6}{|c|}{ Knowledge on causes of Tinea capitis } \\
\hline $\begin{array}{l}\text { Poor personal } \\
\text { hygiene }\end{array}$ & $11(3.0)$ & $34(8.0)$ & $15(4.0)$ & $158(40.0)$ & $181(45.0)$ \\
\hline Poor housing & $32(8.0)$ & $78(19.5)$ & $104(26.0)$ & $127(32.0)$ & $58(14.5)$ \\
\hline Fungal infection & $209(52.4)$ & $139(34.8)$ & $36(9.0)$ & $7(1.8)$ & $8(2.0)$ \\
\hline $\begin{array}{l}\text { Nutritional } \\
\text { deficiency }\end{array}$ & $7(1.8)$ & $37(9.3)$ & $106(26.5)$ & $150(37.6)$ & $99(24.8)$ \\
\hline \multicolumn{6}{|c|}{ Knowledge on signs and symptoms of Tinea capitis } \\
\hline $\begin{array}{l}\text { Itchy, scaly, bald } \\
\text { patches on the head }\end{array}$ & $219(54.9)$ & $152(38.0)$ & $13(3.3)$ & $14(3.5)$ & $1(0.3)$ \\
\hline $\begin{array}{l}\text { Sections of the hair } \\
\text { may break off near } \\
\text { the scalp, leaving } \\
\text { scaly red areas or } \\
\text { bald spots }\end{array}$ & $148(37.0)$ & $203(50.9)$ & $28(7.0)$ & $13(3.3)$ & $7(1.8)$ \\
\hline Brittle hair that easily pulls out & $133(33.3)$ & $174(43.6)$ & $52(13.0)$ & $29(7.3)$ & $11(2.8)$ \\
\hline Painful scalp & $88(22.0)$ & $197(49.4)$ & $71(17.8)$ & $35(8.8)$ & $8(2.0)$ \\
\hline \multicolumn{6}{|c|}{ Knowledge on transmission of Tinea capitis } \\
\hline $\begin{array}{l}\text { Direct contact with } \\
\text { skin of an infected } \\
\text { person (person to } \\
\text { person) }\end{array}$ & $210(52.6)$ & $132(33.1)$ & $34(8.5)$ & $17(4.3)$ & $6(1.5)$ \\
\hline $\begin{array}{l}\text { Contact with infected pets/animal } \\
\text { (pet/ } \\
\text { animal to person) }\end{array}$ & $85(21.3)$ & $181(45.4)$ & $64(16.0)$ & $47(11.8)$ & $22(5.5)$ \\
\hline $\begin{array}{l}\text { Contact with } \\
\text { beddings, clothing } \\
\text { of an infected person } \\
\text { (inanimate item to person) }\end{array}$ & $164(41.1)$ & $174(43.6)$ & $28(7.0)$ & $23(5.8)$ & $10(2.5)$ \\
\hline \multicolumn{6}{|c|}{ Knowledge on risk factors of Tinea capitis } \\
\hline $\begin{array}{l}\text { Age (most } \\
\text { commonly toddler } \\
\text { and school-age } \\
\text { children) }\end{array}$ & $188(47.1)$ & $120(30.1)$ & $50(12.5)$ & $26(6.5)$ & $15(3.8)$ \\
\hline Exposure to pets & $49(12.3)$ & $165(41.3)$ & $94(23.6)$ & $72(18.0)$ & $19(4.8)$ \\
\hline Those who sweat excessively & $45(11.3)$ & $96(24.1)$ & $131(32.8)$ & $77(19.3)$ & $50(12.5)$ \\
\hline $\begin{array}{l}\text { Those participating } \\
\text { in contact sports }\end{array}$ & $64(16.0)$ & $160(40.1)$ & $81(20.3)$ & $64(16.0)$ & $30(7.6)$ \\
\hline $\begin{array}{l}\text { Weakened immune } \\
\text { System }\end{array}$ & $101(25.3)$ & $200(50.1)$ & $48(12.0)$ & $38(9.5)$ & $12(3.0)$ \\
\hline $\begin{array}{l}\text { Sharing hair brushes } \\
\text { and other personal } \\
\text { items }\end{array}$ & $132(33.1)$ & $214(53.6)$ & $27(6.8)$ & $18(4.5)$ & $8(2.0)$ \\
\hline \multicolumn{6}{|c|}{ Knowledge on prevention of Tinea capitis } \\
\hline $\begin{array}{l}\text { Avoid sharing hair brushes and } \\
\text { other personal items }\end{array}$ & $246(61.7)$ & $133(33.3)$ & $11(2.8)$ & $6(1.5)$ & $3(0.8)$ \\
\hline Regular shampooing & $54(13.5)$ & $194(48.6)$ & $76(19.0)$ & $59(14.8)$ & $16(4.0)$ \\
\hline $\begin{array}{l}\text { Avoid petting animals that have } \\
\text { patches on their skin }\end{array}$ & $79(19.8)$ & $174(43.6)$ & $73(18.3)$ & $57(14.3)$ & $16(4.0)$ \\
\hline $\begin{array}{l}\text { Maintain regular checkups for } \\
\text { all pets }\end{array}$ & $84(21.1)$ & $198(49.6)$ & $62(15.5)$ & $47(11.8)$ & $8(2.0)$ \\
\hline Educates the community & $135(33.8)$ & $212(53.1)$ & $38(9.5)$ & $12(3.0)$ & $2(0.5)$ \\
\hline Improve nutrition & $111(27.8)$ & $198(49.6)$ & $61(15.3)$ & $22(5.5)$ & $7(1.8)$ \\
\hline
\end{tabular}




\begin{tabular}{|c|c|c|c|c|c|}
\hline Reduce environmental pollution & $84(21.1)$ & $158(39.6)$ & $76(19.0)$ & $67(16.8)$ & $14(3.5)$ \\
\hline \multicolumn{6}{|c|}{ Overall respondents' knowledge on Tinea capitis } \\
\hline Variable & & & & \multicolumn{2}{|c|}{ Poor } \\
\hline Cause & & & .8) & \multicolumn{2}{|c|}{$360(90.2)$} \\
\hline Signs and symptoms & & & $3.2)$ & \multicolumn{2}{|c|}{$67(16.8)$} \\
\hline Transmission & & & $1.0)$ & \multicolumn{2}{|c|}{$76(19.0)$} \\
\hline Risk factors & & & $3.6)$ & \multicolumn{2}{|c|}{$225(56.4)$} \\
\hline Prevention & & & $9.2)$ & \multicolumn{2}{|c|}{$123(30.8)$} \\
\hline Knowledge on Tinea capitis & & & 4.6) & \multicolumn{2}{|c|}{$181(45.4)$} \\
\hline
\end{tabular}

Data are presented as the frequency of respondents (number) and percentages (\%) of respondents unless otherwise indicated.

Table 3: Respondents' behaviour towards prevention of Tinea capitis

\begin{tabular}{|l|c|c|c|c|c|}
\hline Variable & Very frequently & Frequently & Occasionally & Rarely & Never \\
\hline $\begin{array}{l}\text { I avoid sharing hair brushes } \\
\text { and other personal items }\end{array}$ & $166(41.6)$ & $139(34.8)$ & $61(15.3)$ & $18(4.5)$ & $15(3.8)$ \\
\hline I shampoo hair/ scalp & $65(16.3)$ & $114(28.6)$ & $69(17.3)$ & $75(18.8)$ & $76(19.0)$ \\
\hline I practice good hygiene & $135(33.8)$ & $190(47.6)$ & $56(14.0)$ & $12(3.0)$ & $6(1.5)$ \\
\hline $\begin{array}{l}\text { I avoid petting animals that } \\
\text { have patches on their skin }\end{array}$ & $80(20.1)$ & $104(26.1)$ & $129(32.3)$ & $63(15.8)$ & $23(5.8)$ \\
\hline I carry out checkups for pets & $33(8.3)$ & $102(25.6)$ & $82(20.6)$ & $100(25.1)$ & $82(20.6)$ \\
\hline \multicolumn{2}{|c|}{ Overall respondents' prevention behaviour } & Good & \multicolumn{2}{|c|}{ Poor } \\
\hline \multicolumn{2}{|c|}{ Variable } & \multicolumn{3}{|c|}{161 (40.4) } & $238(59.6)$ \\
\hline
\end{tabular}

Data are presented as frequency (number) and percentages (\%) of respondents; unless otherwise indicated

Table 4: Association of exposure to Tinea capitis, knowledge and prevention behaviour

\begin{tabular}{|c|c|c|c|c|c|}
\hline \multicolumn{6}{|c|}{ Association of exposure to Tinea capitis with knowledge } \\
\hline Variable & $\begin{array}{c}\text { Good knowledge, } \\
\text { n (\%) }\end{array}$ & $\begin{array}{c}\text { Poor knowledge, } \\
\text { n }(\%)\end{array}$ & df & $\chi^{2}$ & $P$-value \\
\hline Not Exposed & $37(17.0)$ & $48(26.5)$ & \multirow{5}{*}{1} & \multirow{5}{*}{5.376} & \multirow{5}{*}{$\mathbf{0 . 0 2}$} \\
\hline Exposed & $181(83.0)$ & $133(73.5)$ & & & \\
\hline & Not Exposed & Exposed & & & \\
\hline $\begin{array}{c}\text { Good knowledge, } \\
\text { n (\%) } \\
\end{array}$ & $37(43.5)$ & $181(57.6)$ & & & \\
\hline $\begin{array}{c}\text { Poor knowledge, } \\
\text { n }(\%)\end{array}$ & $48(56.5)$ & $133(42.4)$ & & & \\
\hline \multicolumn{6}{|c|}{ Association of knowledge on Tinea capitis with prevention behaviour } \\
\hline Variable & $\begin{array}{c}\text { Good practice, } \\
\text { n }(\%)\end{array}$ & $\begin{array}{c}\text { Poor practice, } \\
\text { n }(\%) \\
\end{array}$ & df & $\chi^{2}$ & $P$-value \\
\hline $\begin{array}{c}\text { Good knowledge, } \\
\text { n }(\%) \\
\end{array}$ & $86(53.4)$ & $132(55.5)$ & \multirow{5}{*}{1} & \multirow{5}{*}{0.162} & \multirow{5}{*}{0.687} \\
\hline Poor knowledge, n (\%) & $75(46.6)$ & $106(44.5)$ & & & \\
\hline & $\begin{array}{c}\text { Good knowledge, } \\
\text { n (\%) } \\
\end{array}$ & Poor knowledge, n (\%) & & & \\
\hline Good practice, n (\%) & $86(39.4)$ & $75(41.4)$ & & & \\
\hline Poor practice, n (\%) & $132(60.6)$ & $106(58.6)$ & & & \\
\hline
\end{tabular}

Data shown are number (n) of subjects and proportions $(\%)$ unless otherwise indicated. *cells with $<5$ counts were excluded from the analysis. df, degrees of freedom. $\chi^{2}$, Pearson's Chi-square. 
The poor prevention behaviour towards Tinea capitis observed in the community could be attributed to poor economic status since the majority $(43.4 \%)$ of the study participants had an average monthly income of less than kshs. 5000 , and only $20.3 \%$ were employed. Lack of higher education in the community presented by almost a quarter of the study respondents who had attained post-secondary education could as well be associated to the poor prevention behaviour.

\section{Association of exposure with Knowledge on Tinea capitis}

The study findings revealed that there was no association between respondents' knowledge on $T$. capitis with the prevention behaviour.

The results indicated that exposure to Tinea capitis $\left(\mathrm{X}^{2}(1)=\right.$ 5.376; $\mathrm{p}=0.02)$ was associated to the respondents' knowledge on the disease. The findings mirror (Rennie et al., 2019) which reported association between knowledge and exposure human immunodeficiency virus (HIV) $\left(\mathrm{X}^{2}=104.5\right.$, $\mathrm{p}<0.001)$. The knowledge scores were as well associated with the student's year of study

\section{CONCLUSION}

The study concludes that there is a high burden of Tinea capitis infection in the community. The community has good knowledge on Tinea capitis, although poor knowledge was presented on the cause and risk factors of the disease. Also, the community has poor prevention behaviour towards Tinea capitis.

Furthermore, exposure to Tinea capitis was associated to the respondents' knowledge on the disease. Additionally, community knowledge on Tinea capitis and prevention behaviour were not associated.

\section{RECOMMENDATION}

Due to the high burden of Tinea capitis and poor knowledge in the community, the study recommends for community health education. Emphasis should be put on the cause and risk factors to the disease.

The study findings revealed that there was association between exposure with knowledge on Tinea capitis and therefore this study recommends broader engagement of community members when community education is conducted to increase rate of information dissemination and impact.

\section{REFERENCES}

[1] Abdulrahman, M. A., Hatim, A. A., Abdullah, R. A., Mogharbel, B. F., Fageeha, S. T., Malky, A. M., ... Alzidi, J. A. K. (2017). Assessment of Knowledge, Attitude and Practice toward Acne Vulgaris among Community in Jeddah City. The Egyptian Journal of Hospital Medicine Vol. 66, pp 193-197)

[2] Adesiji, Y. O., Omolade, F. B., Aderibigbe, I. A., Ogungbe, O., Adefioye, O. A., Adedokun, S. A., Adekanle, M. A., \& Ojedele, R. (2019). Prevalence of Tinea Capitis among Children in Osogbo, Nigeria, and the Associated Risk Factors. Diseases (Basel, Switzerland), 7(1), 13. https://doi.org/10.3390/diseases7010013

[3] Aktas, E. \& Esin, M. N. (2016). Skin disease symptoms and related risk factors among young workers in high-risk jobs. Contact Dermatitis. Vol. 75, pp 96-105

[4] Alshehri O. M., Alharbi R. A. \& Alsoraya B. M. (2018). Assessment of knowledge, attitude and practice towards scabies among medical students in Kingdom of Saudi Arabia. The Egyptian Journal of Hospital Medicine. Vol. 73 (6), Page 6897-6899

[5] Bilal, M., Abdell, H., Medawi, A. and Mahmoud, M.A. (2018) Knowledge, Attitude and Practice in Preventing Transmission of Scabies among Nurses Students at Sabia University College Jazan University. Austin Journal of Nursing Health Care. Vol. 5 (1); pp 1043

[6] Bilgili, M. E., Yildiz, H. and Sarici, G. (2013). Prevalence of Skine diseases in a dermatology clinic in Turkey. Across-sectional, retrospective study. Journal of Dermatological Case Reports. Vol. 4; pp 108 - 112. DOI: http://dx.doi.org/10.3315/jdcr.2013.1156

[7] Busia County Integrated Development Plan 2018-2022 -Final Draft

[8] Cochran, W.G. (1963) Sampling Techniques, Wiley, New York.

[9] Guto, J. A., Bii C. C., and Denning D. W. (2016). Emerging Problems in Infectious Diseases. Estimated burden of fungal infections in Kenya. The Journal of Infection in Developing Countries. Vol. 10 (8); pp777-784.

[10] Hay, R., Johns, N. E., Williams, H. C., Bolliger, I. W., Dellavalle, R. P., Margolis, D. J., Marks, R., Naldi, L., Weinstock, M. A., Wulf, S. K. and Michaud C, (2013). The global burden of skin disease in 2010: An analysis of the prevalence and impact of skin conditions. Journal of Invest Dermatology Vol. 134(6); pp 1523-1747.

[11] Hibstu, D. T, and Kebede, D. L. (2017) Epidemiology of Tinea Capitis and Associated Factors among School Age Children in Hawassa Zuria District, Southern Ethiopia, 2016. Journal of Bacteriology and Parasitology Vol. 8 (2); pp 309. doi:10.4172/2155-9597.1000309

[12] Karimkhani, C., Dellavalle, R. P., Coffeng, L. E., Flohr, C., Hay, R. J., Langan, S. M., ... Naghavi, M. (2017). Global Skin Disease Morbidity and Mortality: An Update From the Global Burden of Disease Study 2013. JAMA dermatology, 153(5), 406-412. doi:10.1001/jamadermatol.2016.5538

[13] Laraqui, O., Manar, N., Laraqui, S., Ghailan, T., Deschamps, F., Hammouda, R. and Laraqui, C. E. H. (2018). Prevalence of skin diseases among Moroccan fishermen. International maritime health. Vol. 69 (1); pp 22-27 doi:10.5603/IMH.2018.0004

[14] Mahirah, B. M. Y., Silvita, F. R., Yunita, D. (2015). A Study on Knowledge, Attitude and Practice in Preventing Transmission of Scabies in Pesantren Darul Fatwa, Jatinangor. Althea Medical Journal, Vol. 2 (1) pp 131-137

[15] Mohammed, A. A. A, Shamsun, N., Sami, A. A. \& Ramzy, A. A. (2017). Knowledge, attitude and practice of primary care physicians regarding common dermatological disorder in Abha city, Kingdom of Saudi Arabia. IOSR journal of pharmacy, Vol. 7 (2); pp 89-110

[16] Morowatisharifabad MA, Bayati, F., Rahaei Z., Ebrahimzadeh Ardakani, M., Namayandeh SM.( 2017). Attitude to, knowledge and practice of skin care in older adults in Sarakhs city, and prevalence of some skin problems among the. Elderly health journal. Vol.3 (2); pp 67-73

[17] Moto, J. N., Maingi, J. M., \& Nyamache, A. K. (2015). Prevalence of Tinea capitis in school going children from Mathare, informal settlement in Nairobi, Kenya. BMC research notes, 8, 274. https://doi.org/10.1186/s13104-015-1240-7

[18] Naqvi, A. A., Zehra, F., Ahmad, R, Ahmad, N., Yazdani, N., Usmani, S., Younus, I., Badar, S. and Khan, S. J. (2018). Awareness, knowledge and attitude towards breast cancer, breast screening and early detection techniques among women in Pakistan. Journal of Pakistan Medical Association. Vol. 68, No. 4, April 2018

[19] Ngwogu, A. and Otokunefo, T. V. (2007). Epidemiology of dermatophytoses in a rural community in Eastern Nigeria and review of literature from Africa. Mycopathologica Vol. 164 pp 149-158.

[20] Rennie, T. W., Udjombala, B., Chipeio, M., Kraeker, C., \& Hunter, C. J. (2019). Health students' knowledge and infectious disease exposure: findings from a cross-sectional study in Namibia. International health, 11(6), 616-618. https://doi.org/10.1093/inthealth/ihz052

[21] Yahya, H. (2017).Knowledge, perception, and practice of patients about pityriasis versicolor in Kaduna, North Central Nigeria. International journal of dermatology. Vol. 56(11):1169-1174. doi: 10.1111/ijd.13654.

[22] Yang, X., Shi, X., Chen, W., Zhou, Y., Lionakis, M. S., Kontoyiannis, D. P., \& Liu, W. (2020). First report of kerion (tinea capitis) caused by combined Trichophyton mentagrophytes and Microsporum canis. Medical mycology case reports, 29, 5-7. https://doi.org/10.1016/j.mmcr.2020.05.002 